\title{
Evaluation of Three-dimensional Urban Expansion: A Case Study of Yangzhou City, Jiangsu Province, China
}

\author{
QIN Jing $^{1,2}$, FANG Chuanglin ${ }^{1}$, WANG Yang ${ }^{3}$, LI Guangdong ${ }^{1,2}$, WANG Shaojian ${ }^{1,2}$ \\ (1. Institute of Geographic Sciences and Natural Resources Research, Chinese Academy of Sciences, Beijing 100101, China; 2. Univer- \\ sity of Chinese Academy of Sciences, Beijing 100049, China; 3. Guangzhou Institute of Geography, Guangzhou 510070, China)
}

\begin{abstract}
With rapid urban development in China in the last two decades, the three-dimensional (3D) characteristic has been the main feature of urban morphology. However, the vast majority of researches of urban growth have focused on the planar area (two-dimensional (2D)) expansion. Few studies have been conducted from a 3D perspective. In this paper, the 3D urban expansion of the Yangzhou City, Jiangsu Province, China from 2003 to 2012 was evaluated based on Geographical Information System (GIS) tools and high-resolution remote sensing images. Four indices, namely weighted average height of buildings, volume of buildings, 3D expansion intensity and 3D fractal dimension are used to quantify the 3D urban expansion. The weighted average height of buildings and the volume of buildings are used to illustrate the temporal change of the 3D urban morphology, while the other two indices are used to calculate the expansion intensity and the fractal dimension of the 3D urban morphology. The results show that the spatial distribution of the high-rise buildings in Yangzhou has significantly spread and the utilization of the 3D space of Yangzhou has become more efficient and intensive. The methods proposed in this paper laid a foundation for a wide range of study of 3D urban morphology changes.

Keywords: three-dimensional urban morphology; high-resolution remote sensing image; three-dimensional expansion; three-dimensional fractal; Yangzhou City; China

Citation: Qin Jing, Fang Chuanglin, Wang Yang, Li Guangdong, Wang Shaojian, 2015. Evaluation of three-dimensional urban expansion: a case study of Yangzhou City, Jiangsu Province, China. Chinese Geographical Science, 25(2): 224-236. doi: 10.1007/s11769-014-0728-8
\end{abstract}

\section{Introduction}

Urbanization is one of the most irreversible impacts of human activities on land use (Seto et al., 2011). Scarce land resources are gradually consumed by the urban expansion all over the world. In recent years, China's urbanization has entered a dramatic rapid stage (Shen et al., 2002; Xiao et al., 2006; Wang et al., 2011; Sun P J et al., 2013). With the unprecedented urbanization process, land resources demand is constantly rising. Much pressure on land supply is generated during urban development and construction (Pan et al., 2008). In order to improve the efficiency of land use and allocation, the urban morphology tends to grow higher into the vertical space instead of sprawl larger in the planar space. As a result, the three-dimensional (3D) characteristics have become the main feature of the urban morphology and the three-dimensional growth of urban space has become an important objective of urban growth (Liu et al., 2012). Therefore, quantifying the 3D urban expansion and exploring its spatio-temporal characteristics are of significance for realizing sustainable use of urban land resources.

For a long time, the quantitative researches on urban morphology have focused on the analysis of planar characteristics. The commonly used methods and indi-

Received date: 2013-10-09; accepted date: 2014-03-20

Foundation item: Under the auspices of Major Project of National Social Science Foundation of China (No. 13\&ZD13027), National Science \& Technology Pillar Program During 12th Five-year Plan Period (No. 2012BAJ22B03-04), National Natural Science Foundation of China (No. 41401164)

Corresponding author: FANG Chuanglin. E-mail: fangcl@igsnrr.ac.cn

(C) Science Press, Northeast Institute of Geography and Agroecology, CAS and Springer-Verlag Berlin Heidelberg 2015 
ces include compactness index (Ma et al., 2008; Fan et al., 2009), sprawl intensity (Cai et al., 2007; Fan et al., 2009), spatial metrics (Huang et al., 2007; Pham et al., 2011; Sun C et al., 2013), gradient analysis (Zhang et $a l ., 2004)$ and fractal dimension (Shen, 2002; Herold et al., 2003; Ma et al., 2008). These methods have been used to elaborate the spatial-temporal characteristics of urban growth by analyzing the intensity and speed of expansion, as well as the anisotropy and spatial heterogeneity of expansion. However, the 2D urban morphology evolution can not reflect the spatial pattern change of modern cities which are characterized by all kinds of high buildings. So it is necessary to analyze the urban expansion in a 3D perspective. Due to an absence of data on the geographical distribution of buildings height in space, not much progress has been made in quantitative analysis of the 3D urban morphology. Until now, only a few researchers have made attempts to conduct quantitative research on the 3D urban morphology. Yoshida and Omae (2005) employed the laser radar data to obtain models of urban landscapes and established an index system to conduct quantitative analysis over the central $2 \mathrm{~km} \times 2 \mathrm{~km}$ area of Tokyo. Yu et al. (2010) analyzed the 3D morphology of Houston downtown whose floor area ratio (FAR) and building coverage rate (BCR) were automatically extracted from airborne radar data using the object-oriented method. Pan et al. (2008) estimated the urban building coverage rate using high-resolution remote sensing images and made a comparative analysis among several areas of interest in Shanghai City. Yet, the researches above had mostly focused on the 3D urban morphology in some typical areas of a city rather than a whole city area. Moreover, multi-temporal data had not been adopted to explore the 3D urban expansion. There is still a lack of quantitative investigations on the spatio-temporal changes of the $3 \mathrm{D}$ urban morphology.

In this paper, we designed four quantitative indices, including two primary variables, weighted average height of buildings and volume of buildings, which are used to illustrate the temporal change of 3D urban morphology of Yangzhou City from 2003 to 2012. The other two indices, 3D expansion intensity and 3D fractal dimension, are developed from the above two and exhibit the crucial aspects of spatial change of urban 3D morphology. The primary objective of this paper is to provide a quantitative approach to analyze the temporal and spatial change of 3D urban morphology

\section{Materials and Methods}

\subsection{Study area}

Yangzhou City is located in the middle of Jiangsu Province, the north shore of the lower reaches of the Changjiang (Yangtze) River and the south end of the Changjiang-Huaihe Rivers Plain (Fig. 1). It is one of the most important and vigorous cities in the economic circle of the Changjiang River Delta. Yangzhou City consists of six county-level administrative regions, which are Baoying County, Gaoyou City, Yizheng City, Hanjiang District, Guangling District and Jiangdu District (Fig. 1c). The area of Yangzhou City is approximately $6634 \mathrm{~km}^{2}$ and the census population is about $4.59 \times 10^{6}$ in 2012 (Yangzhou Statistical Bureau, 2013). Both the scale of population and land of Yangzhou are on the upper-middle level of the Chinese cities. With a long evolution history (more than 2500 years), Yangzhou is now a modern city where the urban expansion in the suburban area coexists with the urban renewal in the old urban area, and where the urban gentrification coexists with suburbanization. These features of Yangzhou City are common to the majority of the cities in China. Therefore, Yangzhou is a typical case for the study of 3D urban expansion.

In this paper, the central urban area of the Yangzhou City is selected as the study area. The research scope is confined by the Yangzhou-Liyang Expressway in the west, the Liaojia River in the east, the Qidong-Yangzhou Expressway in the north and the Yiyang River and Wuzhou Road in the south (Fig. 2). The total population of this area had reached about 769200 in 2012. The total area is about $220 \mathrm{~km}^{2}$, while the urban construction area is about $89.26 \mathrm{~km}^{2}$. The urban space is subdivided by referring to the actual urban planning of Yangzhou City and the two classic urban structures proposed by the Chicago school, namely the 'concentric circle structure' and 'fan type structure'. The study area is respectively subdivided into the Ancient Urban Area (AUA), the Old Urban Area (OUA), the New Urban Area (NUA) and the Suburban Area (SUA) with reference to concentric circle structure (Fig. 2a) and into the Ancient Urban Area (AUA), the West Area (WA), the East Area (EA) and the North Area (NA) with reference to fan type structure (Fig. 2b) (Wang et al., 2013). In order to discuss the spatial heterogeneity of urban morphology in 
detail, intersections of different sub-areas are also defined. For example, the intersection of the West Area and the Old Urban Area is called the West Old Urban
Area (WOUA), while the intersection of the East Area and the New Urban Area is called the East New Urban Area (ENUA), etc.

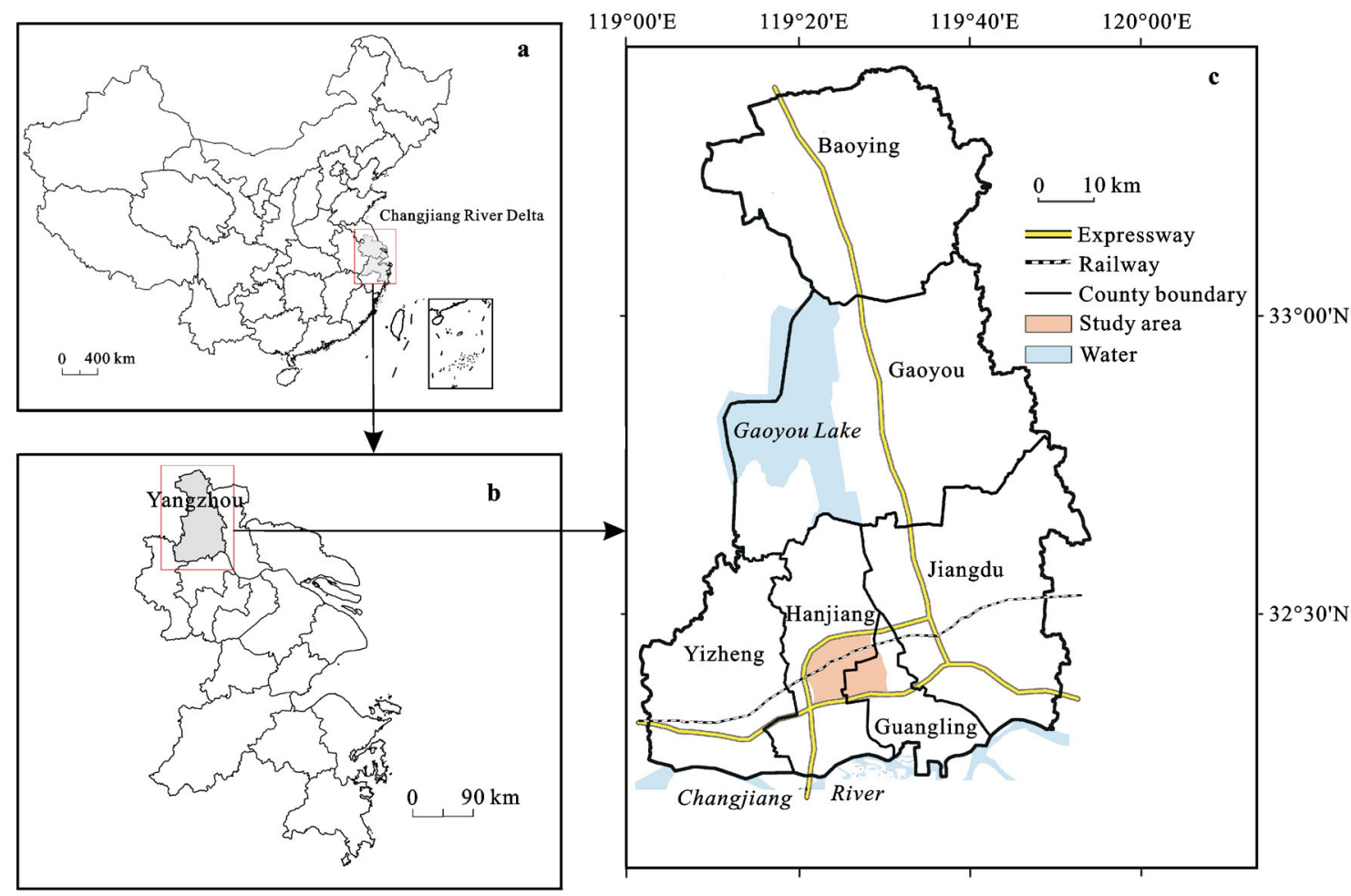

Fig. 1 Location of study area: a) Changjinag River Delta, b) Yangzhou city in Changinag River Delta, c) study area in Yangzhou city

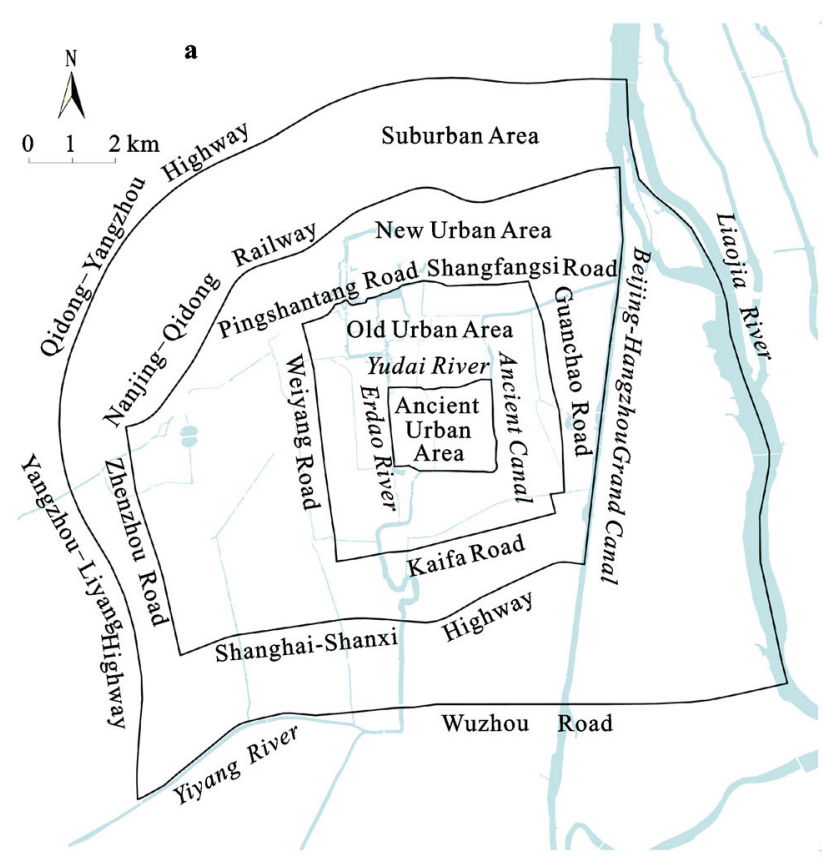

Boundary

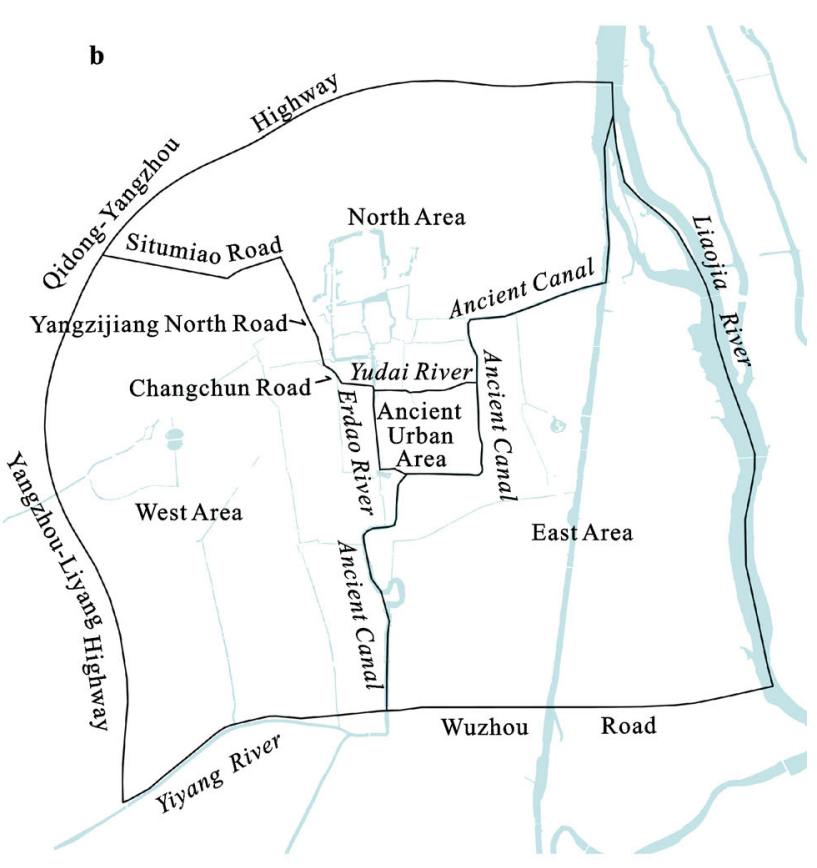

Water

Fig. 2 Space division of study area: a) concentric circle structure; b) fan type structure. Boundaries defining concentric and fan-shaped structures are roads, railways, expressways and rivers of Yangzhou City 


\subsection{Data collection and image processing}

To characterize the 3D urban morphology, the outlines, heights and types of buildings must be acquired. High-resolution remote sensing images of Yangzhou City in 2003 and 2012 are obtained firstly. The images of 2003 and 2012 are the QuickBird data with $0.61 \mathrm{~m}$ resolution and the GeoEye data with $0.5 \mathrm{~m}$ resolution respectively. Then the outlines of buildings are extracted through the object-oriented segmentation of high-resolution remote sensing images, followed by visual inspection and correction. The methods to extract data of building height can be divided into the three categories as follows: 1) Field investigation. High-precision data can be obtained by using this method, but it requires lots of manpower and material resources. Therefore, it is only suitable for the measurement over a small area. 2) Shadow analysis (Massalabi et al., 2004; Dare, 2005; Bai and He, 2011). This method uses the lengths of building shadows on satellite image to retrieve the building heights. Yet, it is still in the initial stage of development, and not applicable for intensive urban buildings and undulating topography. 3) The LIDAR point cloud data processing method (Rottensteiner and Briese, 2002; Rottensteiner, 2003). The building height is obtained by processing point cloud data obtained from airborne LIDAR or mobile LIDAR. While this method can ensure high precision, it is cost-intensive. Balancing the availability and result precision, the Yangzhou 'E-city' 3D model, in which the buildings of Yangzhou City in 2012 are shown in 3D, is used to estimate the heights of buildings in 2012. As no such 'E-city' 3D model is available for 2003, the heights of buildings in 2003 are estimated by referring to the relation between building shadow and building height. Meanwhile, the areas with no change of building height between 2003 and 2012 are used for error control of the height estimation.

The attribute data of buildings and boundary data of different blocks of 2003 and 2012 are obtained from the Status Chart of Land Use in the Planned Areas in the Overall Plan of Yangzhou (2002-2020) and the Status Chart of Land Use in the Planned Areas in the Overall Plan of Yangzhou (2012-2020) respectively, which are provided by Yangzhou Urban Planning and Research Center.

\subsection{Height division of buildings}

In this paper, the individual building is used as a spatial unit for measuring the morphological change of Yangzhou City. Since buildings in the AUA of Yangzhou are characterized by high density and most of them belong to 1-3 storied low-rise buildings, buildings in the same block are treated as one research unit in the AUA. Finally, 12788 buildings in 2003 and 23315 buildings in 2012 are extracted from the high resolution remote sensing images. The buildings are classified as Table 1, according to the height distribution of buildings and with reference to the provisions as follows: the division of building floors in Design Code for Residential Buildings (GB 50096-1999) 2003 Version; the height division of office buildings in Design Code for Office Buildings (JGJ 67-89); and the division of height and floor in Design Code for Civil Buildings (JGJ 37-87).

Due to the limitation on building height, there are no super high-rise buildings over 100 floors in the study area. Therefore, the buildings taller than $54 \mathrm{~m}$ (about 19 floors) were regarded as super high-rise buildings in the paper.

\subsection{Methods}

The urban expansion is a dynamic and random variation process. In the process, not only the urban planner space changes in form of the expansion or shrinkage, but also the height of buildings changes continuously. The 2D expansion of urban space can be characterized by quantitative measurement of the variations of the urban built-up area. As long as the change of urban morphology is inspected in a 3D perspective, the research objects are also expected to be different from that in the 2D perspective. Therefore, the variations of building height and volume are selected as the research objects in this paper. In other words, the $3 \mathrm{D}$ urban expansion is measured through the variations of the height and volume of urban buildings. The reason is that height is the primary feature of 3D urban morphology, while volume reflects both the variation in height and the variation in area.

Table 1 Classification of buildings with different height

\begin{tabular}{lccc}
\hline \multicolumn{1}{l}{ Category } & Height $(\mathrm{m})$ & Floor \\
\hline Low-rise building & $<10$ & $1-3$ \\
Multi-storied building & $10-18$ & $4-6$ \\
& Small high-rise building & $18-36$ & $7-12$ \\
High-rise & High-rise building & $36-54$ & $13-18$ \\
building & Super high-rise building & $>54$ & $>19$ \\
\hline
\end{tabular}




\subsubsection{Weighted average height of buildings}

Because of the variation of the architectural appearances of buildings, the ground areas of buildings are different. In order to improve the accuracy of the result, the area weighted method is chosen to calculate the average building height of the target unit rather than calculating average height directly. The weighted average height (WAH) is the measurement of a centralized trend of building heights. Moreover, it can also be applied for comparative analysis of the same type of buildings under different spatial and temporal scales. So it is a useful index to reveal the evolving process and development tendency of urban morphology. The weighted average height of buildings is calculated by using the following equation:

$$
h_{w, a}=\frac{\sum_{i=1}^{N} A_{i} h_{i}}{\sum_{i=1}^{N} A_{i}}
$$

where $h_{w, a}$ is weighted average height; $A_{i}$ and $h_{i}$ are the ground area and the height of building $i$, respectively; and $N$ is the total number of buildings in the target unit.

\subsubsection{Volume of buildings}

The volume of buildings is the most direct form of the 3D urban morphology expression. It reflects both the height and area variation of 3D urban space. The equation for calculating the volume of buildings is as follows:

$V=\sum_{i=1}^{N} A_{i} \times h_{i}$

where $V$ is the volume of buildings; $A_{i}$ and $h_{i}$ are the ground area and the height of building $i$ respectively; and $N$ is the total number of buildings in the target unit.

\subsubsection{D expansion intensity}

In order to quantify the rate of urban expansion at different stages, an expansion intensity index is introduced. The 2D urban expansion intensity index is defined as the ratio of the expanded area during the research years to the total land use area (Xiao et al., 2006; Hu et al., 2007; Fan et al., 2009). According to the definition of the $2 \mathrm{D}$ urban expansion intensity index, the $3 \mathrm{D}$ expansion intensity index is defined as follows:

$$
U I I_{i}^{n}=\frac{\left(U L V_{i, t+n}-U L V_{i, t}\right)}{n \times T L V_{i}} \times 100, T L V_{i}=A_{i} \times h_{a, i}
$$

where $U I I_{i}{ }^{n}$ is the urban expansion intensity index at the time period $n$ in the target unit $i$; $U L V_{i, t}$ and $U L V_{i, t+n}$ are respectively the total volume of urban buildings at time $t$ and time $t+n$ in the target unit $i$; TLV $V_{i}$ is the volume of the target unit $i ; A_{i}$ is the area of the target unit $i$; and $h_{a, i}$ is the average height of buildings in the target unit $i$.

\subsubsection{D fractal dimension}

There are three methods can be used to calculate the fractal dimension of urban spatial morphology: the first is area-perimeter method, which characterizes the complexity of the shapes of urban boundary (Tannier and Pumain, 2005; Fan et al., 2009); the second is the radius method, which indicates that the attenuation features of spatial distribution departing from the center of the urban to its periphery (Riitters et al., 1995; Frankhauser, 1998; Ma et al., 2008); the third is the box-counting method, which analyzes the overall pattern of urban land use (Benguigui et al., 2000; Shen, 2002; Feng, 2003).

In this paper, we focus on the analysis of the spatial patterns of 3D urban morphology, so the box-counting method is adopted to calculate the fractal dimension. The prerequisite of the box-counting method is that the scale $(r)$ and number of non-empty boxes $(N(r))$ conform to the negative exponential relationship:

$$
N(r) \propto r^{-D}
$$

Batty and Longley (1994) illustrated the 2D box-counting algorithm for calculating the fractal dimension of 2D urban morphology. The 3D box-counting algorithm is an extension of the $2 \mathrm{D}$ algorithm, and its procedure is also similar to that of the $2 \mathrm{D}$ algorithm. The difference is that the urban spatial structure in the $3 \mathrm{D}$ box-counting algorithm requires no information compression and is directly projected onto the $3 \mathrm{D}$ space. Moreover, it is a cube rather than a square used to segment the objects to be measured. That is to say, cubes of different sizes are used to measure the $3 \mathrm{D}$ spaces in order to calculate the number of cubes $(N(r))$ needed to cover the entire 3D urban space. The results are then used to establish a regression curve between the scale $r$ and the number of boxes $N(r)$. The details of the 3D box-counting algorithm are described in the following paragraph.

Assume the entire 3D urban space is $M$ and can be covered completely by a $L \times W \times H$ cube, where $L, W$ and $H$ are the length, width and height of the cube re- 
spectively. Firstly, the $L \times W \times H$ cube is used to measure the $M$ space, and it is obvious that the number of cubes needed $N(r)$ is 1 . Then, for all the following measurements, the dimension of the cube is gradually reduced through a recursive loop, by half each time, and the number of cubes $(N(r))$ required to measure the $M$ space was calculated in turn. Since the ratio of $L \times W \times H$ was constant, no matter which dimension is chosen as the scale of the cube, it will not affect the results. A logarithmic transformation of Equation (4) leads to:

$\lg N(r)=-D \lg r+c$

Then the values of $\lg r$ and $\lg N(r)$ can be obtained from Equation (5). Take them as the horizontal and vertical coordinates to plot diagram using the linear regression equation. The slope of the fitted line is the fractal dimension $D$.

\section{Results}

\subsection{Height and volume changes of buildings}

The statistics of height and volume of different types of buildings in 2003 and 2012 are shown in Table 2. In 2003, the weighted average height was $9.09 \mathrm{~m}$ and was within the scope of the low-rise buildings (Table 1). The commercial and services buildings had the largest average height $(12.40 \mathrm{~m})$, while the residential buildings had the second largest average height $(9.53 \mathrm{~m})$. The commercial and services buildings also had the largest standard deviation of height $(7.08 \mathrm{~m})$, indicating the most significant height fluctuation of commercial buildings. This was because the commercial and services buildings included both low-rise trade markets or supermarkets and high-rise or super high-rise office buildings. The residential buildings accounted for the largest proportion of the total volume $(62.74 \%)$ and were followed by the commercial and services buildings $(23.38 \%)$. The industrial buildings had the smallest proportion of volume and had relatively small average height because most of industrial buildings were factory buildings with 1-2 floors.

In 2012, the overall average height of buildings was $10.23 \mathrm{~m}$, increased by $1.14 \mathrm{~m}$ compared with that in 2003. This result indicated a small average growth rate. Among these buildings, residential buildings with an average height of $12.48 \mathrm{~m}$, increased by $2.95 \mathrm{~m}$ compared with that in 2003 and had the largest growth rate. Commercial and services buildings had an average height of $12.66 \mathrm{~m}$ and a small increase compared with 2003. Industrial buildings showed a slight negative growth, suggesting that the number of low-rise workshops had increased to a certain degree compared with 2003. The residential buildings witnessed the largest increase in volume, followed by industrial buildings.

According to Table 2, the average growth rates of building height and volume were $12.62 \%$ and $119.19 \%$ respectively. Both the horizontal area and vertical height increased, while the expansion of horizontal space was larger than that of vertical space. And the growth rates of the volume of all types of buildings were also much larger than that of the height. The growth patterns of height and volume varied between different types of buildings. The commercial and services buildings showed a large growth in height, while the industrial buildings mainly expanded in the horizontal space. The residential buildings presented a large expansion both in the horizontal and vertical space.

Table 2 Height and volume distribution of different category buildings in 2003 and 2012

\begin{tabular}{|c|c|c|c|c|c|c|c|c|c|}
\hline Building type & Year & $\begin{array}{l}h_{w, a} \\
(\mathrm{~m})\end{array}$ & $\begin{array}{l}\text { Standard deviation } \\
\text { of height }(\mathrm{m})\end{array}$ & $\begin{array}{l}\text { Volume } \\
\left(10^{6} \mathrm{~m}^{3}\right)\end{array}$ & $\begin{array}{l}\text { Volume } \\
\text { ratio (\%) }\end{array}$ & $\begin{array}{l}\Delta h_{w, a} \\
(\mathrm{~m})\end{array}$ & $\begin{array}{c}\Delta V \\
\left(10^{6} \mathrm{~m}^{3}\right)\end{array}$ & $\begin{array}{c}\text { Growth rate } \\
\text { of } h_{w, a}(\%)\end{array}$ & $\begin{array}{c}\text { Growth rate } \\
\text { of } V(\%)\end{array}$ \\
\hline \multirow{2}{*}{ Overall } & 2003 & 9.09 & 6.02 & 1297.41 & - & \multirow{2}{*}{1.14} & \multirow{2}{*}{1546.37} & \multirow{2}{*}{12.62} & \multirow{2}{*}{119.19} \\
\hline & 2012 & 10.23 & 9.29 & 2843.78 & - & & & & \\
\hline \multirow{2}{*}{ Residential } & 2003 & 9.53 & 5.57 & 814.04 & 62.74 & \multirow{2}{*}{2.95} & \multirow{2}{*}{1035.89} & \multirow{2}{*}{30.99} & \multirow{2}{*}{127.30} \\
\hline & 2012 & 12.48 & 9.70 & 1849.94 & 65.05 & & & & \\
\hline \multirow{2}{*}{$\begin{array}{l}\text { Commercial } \\
\text { and Services }\end{array}$} & 2003 & 12.40 & 7.08 & 303.32 & 23.38 & \multirow{2}{*}{0.26} & \multirow{2}{*}{198.36} & \multirow{2}{*}{2.07} & \multirow{2}{*}{65.40} \\
\hline & 2012 & 12.66 & 8.17 & 501.67 & 17.64 & & & & \\
\hline \multirow{2}{*}{ Industry } & 2003 & 5.47 & 1.56 & 175.76 & 13.55 & \multirow{2}{*}{-0.01} & \multirow{2}{*}{305.47} & \multirow{2}{*}{-0.04} & \multirow{2}{*}{173.80} \\
\hline & 2012 & 5.46 & 1.84 & 481.24 & 16.92 & & & & \\
\hline \multirow{2}{*}{ others } & 2003 & 5.97 & 5.29 & 4.29 & 0.33 & \multirow{2}{*}{-0.02} & \multirow{2}{*}{6.61} & \multirow{2}{*}{-0.32} & \multirow{2}{*}{154.10} \\
\hline & 2012 & 5.95 & 5.34 & 10.90 & 0.38 & & & & \\
\hline
\end{tabular}

Notes: $h_{w, a}$ is the weighted average height of buildings showed in Equation (1); $\Delta h_{w, a}$ is the height growth of Yangzhou City from 2003 to $2012 ; \Delta V$ is the volume growth of Yangzhou City from 2003 to 2012 


\subsection{Spatial expansion}

The 3D morphology of Yangzhou City in 2003 (Fig. 3a) and 2012 (Fig. 3b) are illustrated respectively using ArcScene based on the height data of buildings. It is shown in Fig. 3a that the high-rise buildings in 2003 were mainly distributed in the WOUA. Most of the buildings in the EA were multi-storied and low-rise buildings except for a few high-rise buildings. The buildings in the NA and AUA were mostly low-rise and multi-storied buildings. The 3D urban morphology was featured by uneven distribution of a few high-rise buildings among low-rise buildings and multi-storied buildings. The high-rise buildings were mainly concentrated in the WUA. This is because the WUA has been the main direction of urban development of Yangzhou since 1990.

As shown in Fig. 3b, buildings in the AUA remained mostly unchanged in 2012. The high-rise buildings in the WA were concentrated in the West New Urban Area (WNUA) and the West Suburban Area (WSUA), while in the EA and NA the high-rise buildings were clustered in the ENUA and the North New Urban Area (NNUA). Buildings in the AUA remained mostly unchanged. The distribution of high-rise buildings was relatively concentrated in the WA, ENUA and NNUA. And the highrise buildings presented a trend of dispersed distribution. Such change of the 3D urban spatial pattern could be attributed to the implementation of the urban development strategy of Yangzhou since 2003, in which the main development direction is the south, and the east and west are the secondary development directions. As a result, besides the WA, the city was mainly expanded in the east and south direction. Therefore, with many new high-rise buildings constructed, the EOUA and ENUA became a concentrated area of high-rise buildings as well. Due to the reconstruction policy of the OUA, many old low-rise buildings were removed and high-rise buildings were constructed in this area. Consequently, besides the expansion in the outskirts, the high-rise buildings also expanded in the inner city. Meanwhile, two industrial parks of Yangzhou and an economic development zone were located in the northern outskirt and the southwestern outskirt. These areas were characterized by clustering of low-rise factory buildings. It can be seen that the regional development orientation which led to agglomeration of different type buildings in different areas, finally results in the spatial differentiation of Yangzhou's 3D morphology.

\subsection{Urban expansion in two directions}

The distribution of buildings heights along two different directions was analyzed to inspect the directional characteristics of urban expansion (Fig. 4). The 3D urban morphology changes in the east-west direction was inspected along the Wenchang Road, while the morphology in the north-south direction was inspected along the Youyi Road-the Fenghuangqiao Street-the Beimenwai Street-the Wenhe Road-the Lianhuachi Road-the Middle Jiangyang Road-the Andun River-the Ancient Canal. The raster images of 2003 and 2012 with $10 \mathrm{~m}$ resolution are obtained by rasterizing the vector data. The building heights along the two directions were obtained by projecting the heights of buildings within a $500 \mathrm{~m}$ wide buffer area of the two axes.

The pulse-shaped distribution pattern of building height along the west-east direction in 2003 (Fig. 4a) was featured by low height in the middle and the SUA

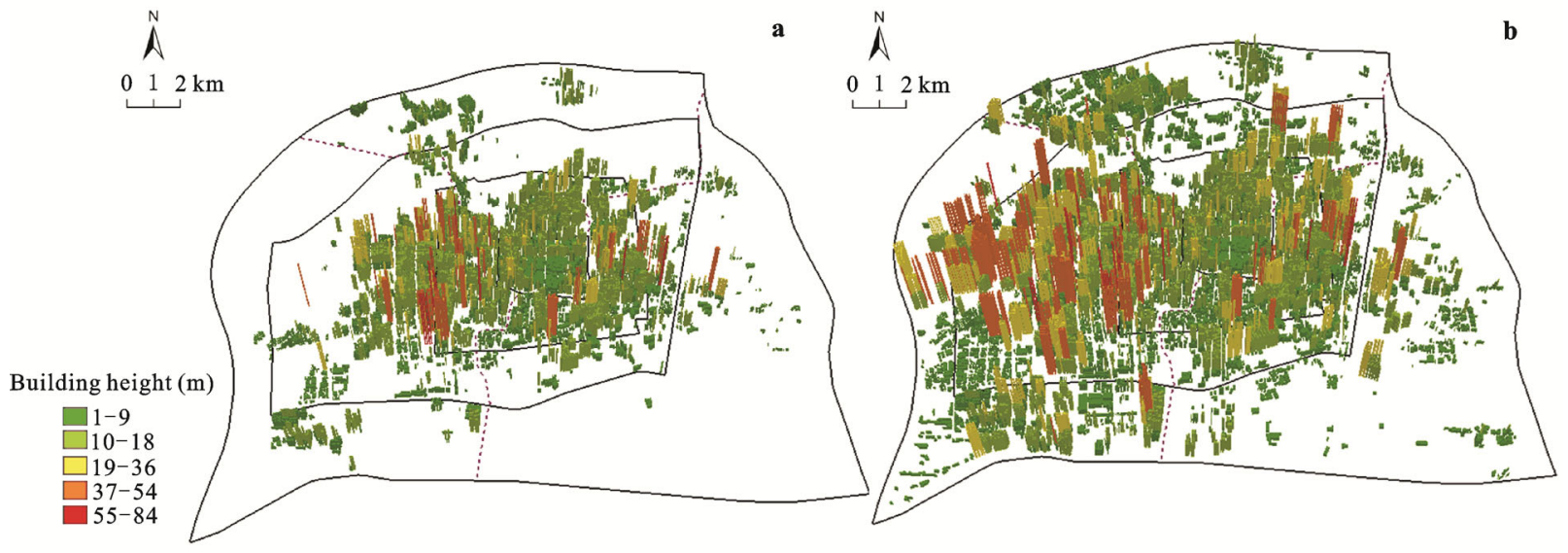

Fig. 3 Three-dimensional models of Yangzhou City: a) 2003; b) 2012 
and high height in the OUA and the NUA. The number of high-rise buildings in the west was larger than that in the east. The building heights presented a three stepsshaped distribution pattern, with the dividing lines at $17 \mathrm{~m}$ (6 floors) and $33 \mathrm{~m}$ (12 floors), and two peaks in the WOUA and EOUA. As the city had expanded from downtown to outskirts, the projected curve of building height in 2012 was also extended from the WNUA to the WSUA. A majority of the newly constructed buildings were about $50 \mathrm{~m}$ in height. At the same time, some high-rise buildings were built in the OUA and NUA, as well as some old buildings were renovated in the OUA. The tallest building was Jinling Hotel $(84 \mathrm{~m})$ in the WNUA. The height of the buildings located in the EOUA, NUA and SUA was taller than that in 2003, while the height of the buildings in AUA remained unchanged. The buildings in the east-west showed that the height distribution pattern was low in the middle, high in the west, and moderate in the east. The building height presented a four steps-shaped distribution pattern, with the dividing lines at $17 \mathrm{~m}$ (6 floors), $33 \mathrm{~m} \mathrm{(12}$ floors) and $50 \mathrm{~m}$ (18 floors). Three peaks emerged in WOUA and WNUA and ENUA.

Figure $4 \mathrm{~b}$ shows that building height had changed at both sides of the south-north direction. The south-north projection of building heights in 2003 varied slightly, and the overall height was low. The building height presented a two steps-shaped distribution pattern, with the dividing line at $17 \mathrm{~m}$ (6 floors), and two peaks of building height were formed respectively in the NOUA and SOUA. Since there was some undeveloped land between the NNUA and NSUA, the projection curve was not complete. The 2012 projection curve, compared with that in 2003, was extended evidently, and the building height increased significantly. This was because high-rise buildings were constructed in the NNUA and SOUA. The height distribution of the buildings was similar in the north and south. The building height in 2012 was featured by a three steps-shaped distribution pattern, with the dividing lines at $17 \mathrm{~m}$ (6 floors) and $33 \mathrm{~m}$ (12 floors). Two height peaks emerged in the SOUA and one height peak in the NNUA.
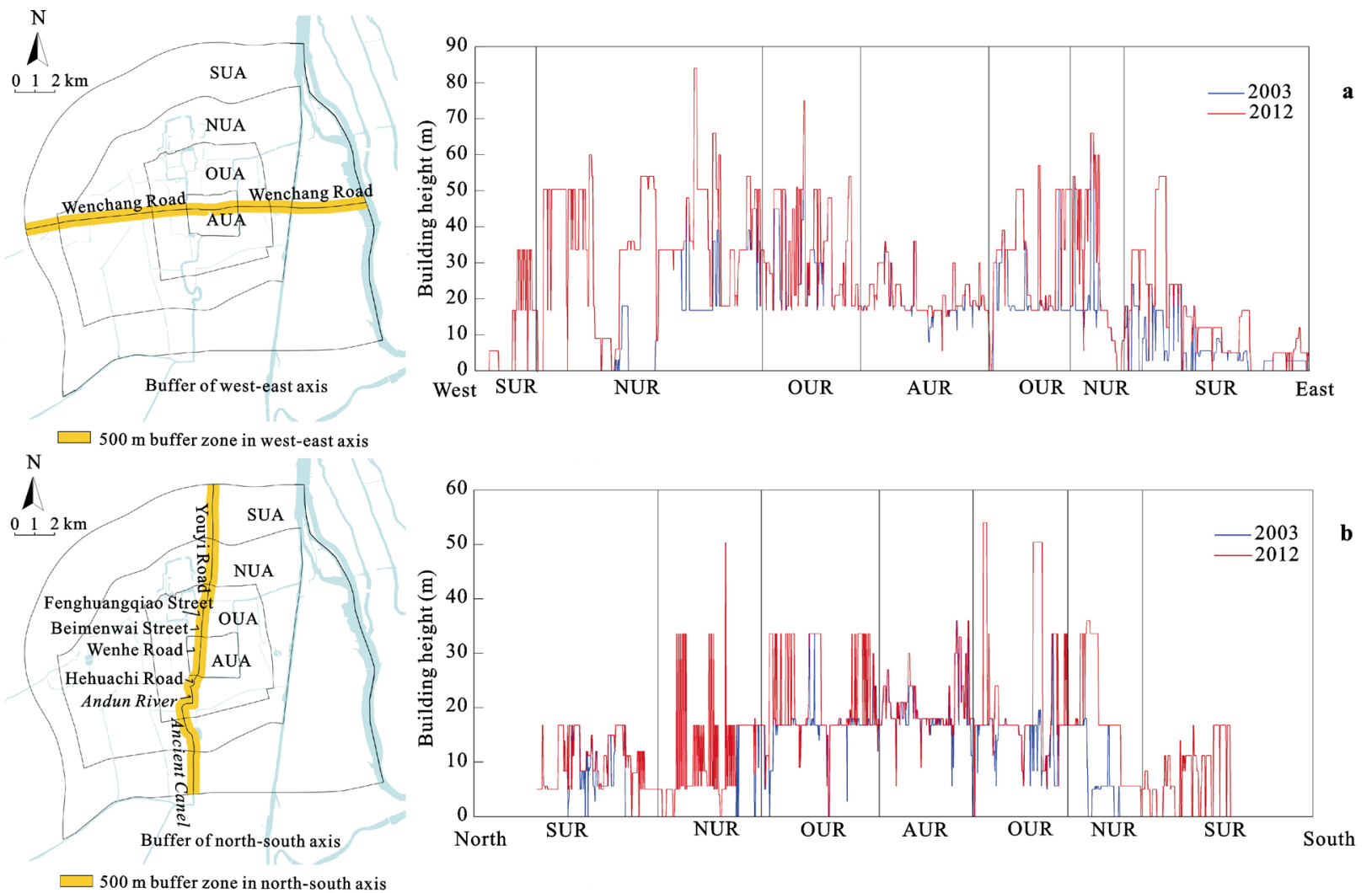

Fig. 4 Building height projection of Yangzhou City: a) Building height projection in west-east direction; b) Building height projection in north-south direction. SUA, NUA, OUA, AUA represent the suburban area, new urban area, old urban area, and ancient urban area, respectively 


\subsection{D urban expansion intensity}

Grid analysis method is a spatial measurement method used to calculate each grid in the study areas by arranging evenly uniform grid points in the entire area and taking such grids as the basic unit to reflect the spatial heterogeneity of urban expansion. In this paper, the 300 $\mathrm{m} \times 300 \mathrm{~m}$ grid is chosen to cover the study area, and the growth intensity index is calculated in each grid according to Equation (4). The natural fracture method is used to divide the index into five levels as follows: high-speed growth, medium-speed growth, slow growth, zero growth and negative growth (Fig. 5).

Figure 5 shows that the research areas with the highest expansion intensity were mainly concentrated in the west of WNUA and WSUA. The high-speed growth of building volume in the south WNUA and WSUA was due to the development of economic development zone and Hanjiang Industrial Park. The growth intensities were also higher in the ENUA, NNUA and Jiangyang Industrial Park. Besides some undeveloped areas in the SUA, AUA and OUA also showed low or zero growth intensity. Moreover, the growth intensity in a few grids of the OUA was negative. That was because the development of the AUA was strictly prohibited in Yangzhou City. And in the reconstruction of the OUA during the past ten years, buildings in some places were demolished without construction immediately. In addition, the urban architectural volume of scenic spots, such as the Slender West Lake, remained unchanged.

\subsection{D Fractal dimension}

The 3D fractal dimension of urban morphology of Yangzhou are calculated by using Matlab program based on the raster data of building heights in Yangzhou. The

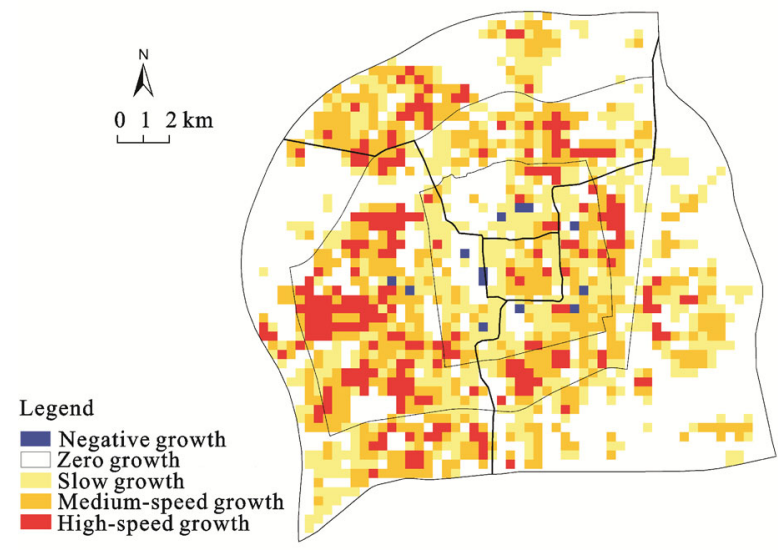

Fig. 5 3D morphology expansion intensity in Yangzhou City initial scale is decided by the boundary rectangle of the research area and the height of the tallest buildings. That is to say, the 3D urban space of Yangzhou could be completely covered by a $17500 \mathrm{~m} \times 17500 \mathrm{~m} \times 84 \mathrm{~m}$ cube. For the initial scale, the cube with the size of $17500 \mathrm{~m} \times 17500 \mathrm{~m} \times 84 \mathrm{~m}$ is selected. Then the volume of the cube is halving each time. The number of non-empty boxes $N(r)$ is calculated at different scale $r$. The logarithm of the values is taken, with $\ln r$ and $\ln N(r)$ as the horizontal axis and vertical axis respectively to draw the scatter plot. The fitted straight line by Equation (5) is shown in Fig. 6. And the absolute value of its slope is the fractal dimension $D$ of Yangzhou 3D morphology.

The linear regression equation and the corresponding inspection parameters converted from the power exponent model are shown in Fig. 6. We can see that the range of points has a good linear distribution trend, with all the coefficient of determinations $R^{2}$ above 0.99 . In particular, $R^{2}$ is as high as 0.9998 of the overall buildings in 2012. The fractal characteristic of the 3D urban morphology of Yangzhou is thus verified. The fractal dimension of the overall buildings had increased from 2.2954 in 2003 to 2.4117 in 2012, indicating that Yangzhou City had a harmonious development. The 3D morphology of Yangzhou City did not only expand to the outskirts, but also implemented the renovation of its old urban areas during the 10 years. As a consequence, the utilization of the 3D space became more efficient and compact, and urban construction land was distributed more uniformly. Among the buildings with different functions, the fractal dimension of residential buildings, industrial buildings and commercial and service buildings all increased. The fractal dimension of residential buildings was the largest. But the fractal dimension of all types of buildings were less than the fractal dimension of the overall buildings, which was consistent with the $2 \mathrm{D}$ inclusion principle of land use fractal dimension. The fractal dimension of different kinds of urban land use should not be higher than the fractal dimension of the overall urban morphology (Feng, 2003).

The fractal dimension of residential buildings witnessed a great increase. The increase indicated that the residential buildings were no longer concentrated in the AUA and OUA, but expanded greatly to the NUA and SUA, resulting in a more uniform spatial distribution of residential land. Meanwhile, the increase number of 

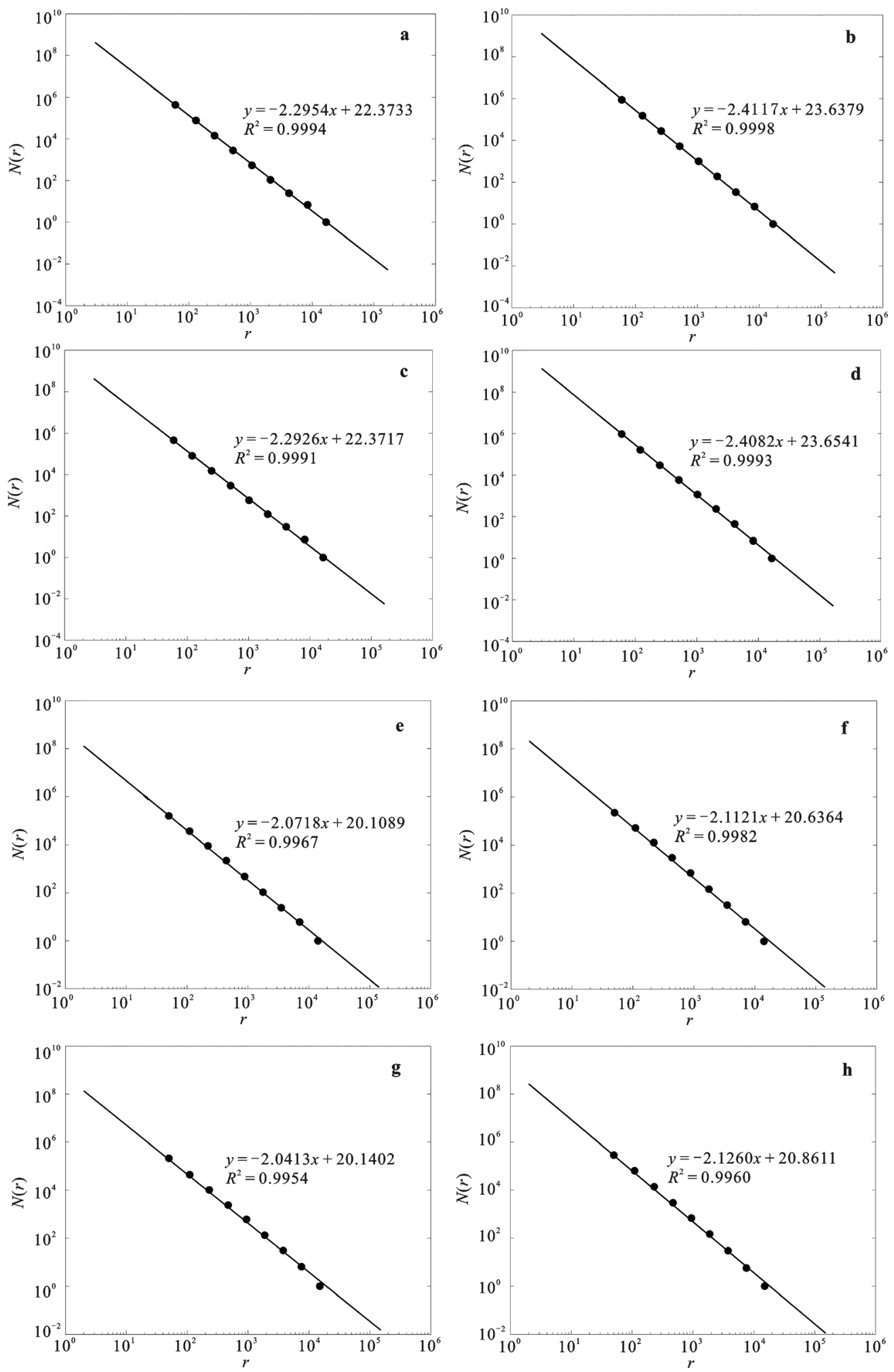

Fig. 6 3D fractal morphology of Yangzhou: a) 2003 Overall buildings; b) 2012 Overall buildings; c) 2003 residential buildings; d) 2012 residential buildings; e) 2003 commercial and service buildings; f) 2012 commercial and service buildings; g) 2003 industry buildings; h) 2012 industry buildings. $N(r)$ means number of non-empty boxes; $r$ means scale

high-rise buildings (included the renovation of urban villages in the OUA and the new constructed high-rise buildings in the NUA and SUA) also pushed up the fractal dimension of residential buildings. The fractal 
dimension growth of residential buildings played an important role in the fractal dimension growth of overall urban buildings. The fractal dimension increase of industrial buildings was related to industrial suburbanization. On one hand, the relocation of Yangzhou's industrial enterprises from the NUA directly caused the industrial suburbanization, leading to the concentrated distribution of most industrial buildings in the suburban industrial parks and economic development zones. But the problems of nearby relocation, scattered relocation and repeated relocation, which led the industrial buildings scatter in the urban area, still existed during the process of industrial suburbanization. As a result, the fractal dimension of industrial buildings failed to reduce in 2012 in spite of the concentrated distribution, but increased compared to that in 2003. The fractal dimension growth of commercial and service buildings was mainly due to the increase of high-rise commercial buildings, such as the high-rise business administrative centers in Guangling and Jinghua trade area of Yangzhou City.

\section{Discussion}

\subsection{Guiding role of urban spatial development strategy and urban planning}

Since the strategy of 'Protecting the AUA and building new urban area in the west' was proposed in the 1990s, the development of Yangzhou has been primarily characterized by a west-oriented fan-shaped expansion pattern. As a result, the WA becomes a cluster area of newly constructed buildings, among which residential and public buildings are the majority and have the most evident 3D expansion. Since 2003, the third round of overall urban development planning was implemented and the development strategy of Yangzhou changed to 'Developing primarily in the south and secondarily in the east and west'. The city began to develop in the south and east area although the WA was still the core area of construction. The Yangzhou City mainly expanded towards the east along with the launch of several major construction projects in 2010, including Guangling District, Jinghang Heart and the east extension of Wenchang Road. Since then, the EOUA and ENUA have many high-rise buildings rose in and became a concentrated area of high-rise buildings. Meanwhile, due to the reconstruction policy of the OUA, many old low-rise buildings were removed and high-rise buildings were constructed in this area. The intensive land use and the change of land use led to the 3D urban expansion of Yangzhou City.

\subsection{Promoting role of industrial development and urbanization}

The real estate, industry, commerce and service industry play different roles in the 3D urban expansion of Yangzhou. Firstly, the 3D expansion of the residential land was promoted by the development of real estate. The rapid progresses of urbanization and accelerated growth of population have stimulated the prosperity of real estate. Due to the scarcity and high price of land supply in the core urban area, many new projects of real estate are moved to the NUA and SUA, and the renovation of residential buildings in the OUA is launched at a large scale. In order to enlarge land use intensification and get more commercial benefits, these new residential buildings are commonly high-rise buildings with high floor area ratio. The $3 \mathrm{D}$ urban space is expanded greatly in height due to the development of real estate. Secondly, the industrial progresses have promoted the urban space to expand to the outskirts. Many industrial enterprises are seeking for more development space and the government intends to reduce the influence of pollutants on urban environment. Therefore, industrial buildings are massively relocated to the suburb. In addition, along with the expansion of the original and new functions of the city to its peripheral areas, the urban space is further expanded. Thirdly, the development of the commerce and service industry promotes the expansion of urban space in height in certain areas. Generally speaking, these areas are turned into the renovated areas or urban business centers. These areas are suitable for commercial and service industries such as finance, hotels and business due to the convenient transportation and frequent business activities. And these areas are also clustered with high-rise buildings because the limited space and expensive land price.

\subsection{Constraint role of natural conditions and pro- tection of famous historic and cultural relics}

The expansion of the 3D urban morphology in any city is inevitably constrained by natural conditions such as rivers and mountains. In Yangzhou, the influence of natural conditions is mainly reflected in the interruption of the continuity of the 3D urban morphology by the 
Beijing-Hangzhou Grand Canal, the ancient canals, the Slender West Lake and other water bodies. Due to the protection of famous historical and cultural relics, such as the AUA and the Slender West Lake in the OUA, the expansion of 3D urban space is kept at a distance from the specific historic districts. The AUA of Yangzhou City is one of the two protected zones specified in the 'Regulation on Protection of Famous Historical and Cultural Relics' in Yangzhou City. In order to protect the overall landscape and historic structure of the AUA, a strict restriction is placed on the increase of the height of buildings in the AUA. As a result, the AUA is still mainly composed of low-rise buildings and multi-storied buildings, with little change to its original appearance from 2003 to 2012. To protect the Slender West Lake, the Daming Temple and the Buddha Mountain in the 'Shugang-Slender West Lake Key Scenic Spot', not only the construction of different types of buildings in these areas is strictly prohibited but also the construction activities are constrained in the surrounding protected zones. Thus, the 3D expansion in these areas is restricted.

\section{Conclusions}

This paper describes the temporal and spatial change of 3D urban morphology of the Yangzhou City, and demonstrates that urban spatial morphology can be effectively and quantitatively assessed based on GIS and high resolution remote sensing images. Four indices of 3D urban morphology are proposed referring to the measures of 2D urban morphology. Wherein, a 3D expansion intensity index is designed for measuring the growth rate of urban expansion at different stages, and a 3D box-counting method is creatively applied in buildings fractal dimension measurement. The methods proposed in this paper are expected to become a foundation for a wide range of 3D urban expansion studies.

The results show that Yangzhou City had experienced expansion both in the horizontal and vertical space over the past ten years. The growth rate of building height was around $12.62 \%$, while the growth rate of volume was around $119.19 \%$. High-rise buildings were mainly distributed in the West Area (WA) in 2003, but spread to the East Area (EA) and the North New Urban Area (NNUA) in 2012. The height distribution of buildings in the east-west direction showed a pattern of low in the middle and highest in the west, followed by the second highest in the east. However, no obvious pattern of variation of building height was found in the north-south direction. The areas with the highest expansion intensity were centralized in the West New Urban Area (WNUA), the West Suburban Area (WSUA), the North New Urban Area (NNUA) and the East New Urban Area (ENUA), while the Ancient Urban Area (AUA) and Old Urban Area (OUA) showed a low or zero growth intensity. What is more, some part of the OUA had negative growth intensity. It was also found that the growth pattern of height and volume varied among different types of building. Commercial and service buildings mainly showed height growth, while industrial buildings mainly expanded in volume. Residential buildings showed large expansion in both height and volume.

In addition, the results of fractal dimension calculation show that the 3D urban morphology of Yangzhou City is fractal. The fractal dimension of urban morphology increased significantly in 2012 compared with that in 2003. The fractal dimension of different types of buildings all increased, among which residential buildings was the largest. The increase in fractal dimension indicates that the utilization of $3 \mathrm{D}$ spaces became more efficient and compact.

Three factors were suggested to be responsible for the growth of the 3D urban space of the Yangzhou City, which are the guiding role of urban spatial development strategy and urban planning, the promoting role of industrial development and urbanization, and the constraint role of natural conditions and protection of famous historic and cultural relics.

\section{Acknowledgements}

We are grateful to Yangzhou Urban Planning and Research Center for providing valuable data.

\section{References}

Bai Y Q, He G J, 2011. Application of region growing algorithm in extracting heights of buildings from high resolution satellite images. In: Image and Signal Processing (CISP), 2011 4th International Congress on. IEEE, 2: 879-882. doi: 10.1109/ CISP.2011.6100334

Batty M, Longley P, 1994. Fractal Cities: A Geometry of Form and Function. London: Academic Press.

Benguigui L, Czamanski D, Marinov M et al., 2000. When and where is a city fractal? Environment and Planning B: Planning and Design, 27(4): 507-519. doi: 10.1068/b2617

Cai B, Zhang Z, Liu B et al., 2007. Spatial-temporal changes of 
Tianjin urban spatial morphology from 1978 to 2004. Journal of Geographical Sciences, 17(4): 500-510. doi: 10.1007/ s11442-007-0500-4

Dare P M, 2005. Shadow analysis in high-resolution satellite imagery of urban areas. Photogrammetric Engineering and Remote Sensing, 71: 169-177.

Fan F, Wang Y, Qiu M et al., 2009. Evaluating the temporal and spatial urban expansion patterns of Guangzhou from 1979 to 2003 by remote sensing and GIS methods. International Journal of Geographical Information Science, 23(11): 1371-1388. doi: 10.1080/13658810802443432

Frankhauser P, 1998. The fractal approach. A new tool for the spatial analysis of urban agglomerations. Population: An English Selection, 10: 205-240.

Herold M, Goldstein N C, Clarke K C, 2003. The spatiotemporal form of urban growth: Measurement, analysis and modeling. Remote Sensing of Environment, 86(3): 286-302. doi: 10.1016/S0034-4257(03)00075-0

Hu Z L, Du P J, Guo D Z, 2007. Analysis of urban expansion and driving forces in Xuzhou city based on remote sensing. Journal of China University of Mining and Technology, 17(2): 267-271. doi: 10.1016/S1006-1266(07)60086-8

Huang J, Lu X, Sellers J M, 2007. A global comparative analysis of urban form: Applying spatial metrics and remote sensing. Landscape and Urban Planning, 82(4): 184-197. doi: 10. 1016/j.landurbplan.2007.02.010

Feng J, 2003. Spatial-temporal evolution of urban morphology and land use structure in Hangzhou. Acta Geographica Sinica, 58(3): 343-353. (in Chinese)

Liu S, Fan X, Wen Q et al., 2012. Simulated impacts of 3D urban morphology on urban transportation in megacities: Case study in Beijing. International Journal of Digital Earth, (ahead-ofprint): 1-22. doi: 10.1080/17538947.2012.740079

Ma R, Gu C, Pu Y et al., 2008. Mining the urban sprawl pattern: A case study on Sunan, China. Sensors, 8(10): 6371-6395. doi: $10.3390 / \mathrm{s} 8106371$

Massalabi A, He D C, Benie G B et al., 2004. Detecting information under and from shadow in panchromatic Ikonos images of the city of Sherbrooke. In Geoscience and Remote Sensing Symposium, 2004. IGARSS'04. Proceedings. 2004 IEEE International, 3: 2000-2003. doi: 10.1109/IGARSS. 2004.1370740

Pan X Z, Zhao Q G, Chen J et al., 2008. Analyzing the variation of building density using high spatial resolution satellite images: The example of Shanghai City. Sensors, 8(4): 2541-2550. doi: 10.3390/s8042541

Pham H M, Yamaguchi Y, Bui T Q, 2011. A case study on the relation between city planning and urban growth using remote sensing and spatial metrics. Landscape and Urban Planning, 100: 223-230. doi: 10.3390/s8042541

Riitters K H, O'neill R, Hunsaker C et al., 1995. A factor analysis of landscape pattern and structure metrics. Landscape Ecology, 10(1): 23-39. doi: 10.1007/BF00158551

Rottensteiner F, 2003. Automatic generation of high-quality building models from lidar data. Computer Graphics and
Applications, IEEE, 23(6): 42-50. doi: 10.1109/MCG.2003. 1242381

Rottensteiner F, Briese C, 2002. A new method for building extraction in urban areas from high-resolution LIDAR data. International Archives of Photogrammetry Remote Sensing and Spatial Information Sciences, 34: 295-301.

Seto K C, Fragkias M, Güneralp B et al., 2011. A meta-analysis of global urban land expansion. PlosOne, 6(8): e23777. doi: 10.1371/journal.pone.0023777

Shen G, 2002. Fractal dimension and fractal growth of urbanized areas. International Journal of Geographical Information Science, 16(5): 419-437. doi: 10.1080/13658810210137013

Shen J, Wong K, Feng Z, 2002. State-sponsored and spontaneous urbanization in the Pearl River Delta of south China, 1980-1998. Urban Geography, 23(7): 674-694. doi: 10.2747/ 0272-3638.23.7.674

Sun C, Wu Z F, Lv Z Q et al., 2013. Quantifying different types of urban growth and the change dynamic in Guangzhou using multi-temporal remote sensing data. International Journal of Applied Earth Observation and Geoinformation, 21: 409-417. doi: 10.1016/j.jag.2011.12.012

Sun P J, Song W, Xiu C L et al., 2013. Non-coordination in China's urbanization: Assessment and affecting factors. Chinese Geographical Science, 23(6): 729-739. doi: 10.1007/ s11769-013-0634-5

Tannier C, Pumain D, 2005. Fractals in urban geography: A theoretical outline and an empirical example. Cybergeo: European Journal of Geography. doi: 10.4000/cybergeo.3275

Wang Deli, Fang Chuanglin, Gao Boyang et al., 2011. Measurement and spatio-temporal distribution of urbanization development quality of urban agglomeration in China. Chinese Geographical Science, 21(6): 695-707. doi: 10.1007/s11769011-0477-X

Wang Y, Fang C L, Sheng C Y, 2013. Spatial differentiation and model evolution of housing prices in Yangzhou. Acta Geographic Sinica, 68(8): 1082-1096. (in Chinese)

Xiao J, Shen Y, Ge J et al., 2006. Evaluating urban expansion and land use change in Shijiazhuang, China, by using GIS and remote sensing. Landscape and Urban Planning, 75(1-2): 69-80. doi: 10.1016/j.landurbplan.2004.12.005

Yangzhou Statistical Bureau, 2013. Yangzhou Statistical Yearbook. Beijing: China Statistics Press.

Yoshida H, Omae M, 2005. An approach for analysis of urban morphology: Methods to derive morphological properties of city blocks by using an urban landscape model and their interpretations. Computers, Environment and Urban Systems, 29(2): 223-247. doi: 10.1109/IGARSS.2004.1370740

$\mathrm{Yu} \mathrm{B}$, Liu H, Wu J et al., 2010. Automated derivation of urban building density information using airborne LiDAR data and object-based method. Landscape and Urban Planning, 98(3-4): 210-219. doi: 10.1016/j.landurbplan.2010.08.004

Zhang $\mathrm{L}$, Wu J, Zhen Y et al., 2004. A GIS-based gradient analysis of urban landscape pattern of Shanghai metropolitan area, China. Landscape and Urban Planning, 69(1): 1-16. doi: 10.1016/j.landurbplan.2003.08.006 